\title{
Role of glutathione in immunity and inflammation in the lung
}

This article was published in the following Dove Press journal:

International Journal of General Medicine

24 January 2011

Number of times this article has been viewed

\section{Pietro Ghezzi}

Brighton and Sussex Medical School, Trafford Centre, Falmer, Brighton, UK

Correspondence: Pietro Ghezzi Division of Clinical and Laboratory Investigation, Brighton and Sussex Medical School, Trafford Centre, Falmer, BNI 9RY, United Kingdom Tel $+44(0)$ I 273873 | I 2

Fax $+44(0)$ | 27387672 I

Email p.ghezzi@bsms.ac.uk
Abstract: Reactive oxygen species and thiol antioxidants, including glutathione (GSH), regulate innate immunity at various levels. This review outlines the redox-sensitive steps of the cellular mechanisms implicated in inflammation and host defense against infection, and describes how GSH is not only important as an antioxidant but also as a signaling molecule. There is an extensive literature of the role of GSH in immunity. Most reviews are biased by an oversimplified picture where "bad" free radicals cause all sorts of diseases and "good" antioxidants protect from them and prevent oxidative stress. While this may be the case in certain fields (eg, toxicology), the role of thiols (the topic of this review) in immunity certainly requires wearing scientist's goggles and being prepared to accept a more complex picture. This review aims at describing the role of GSH in the lung in the context of immunity and inflammation. The first part summarizes the history and basic concepts of this picture. The second part focuses on GSH metabolism/levels in pathology, the third on the role of GSH in innate immunity and inflammation, and the fourth gives 4 examples describing the importance of GSH in the response to infections.

Keywords: antioxidants, oxidative stress, sepsis, infection, cysteine

\section{Oxidative damage and antioxidant defense, inflammation, and immunity Reactive oxygen species and oxidative stress}

While the oxidative deterioration of lipids has been known for a long time, it was only in the late 1960s that we became aware of the importance of these chemical processes in pathology and toxicology with the finding that lipid peroxidation or rancidification occurred also in biological systems. ${ }^{1,2}$ The expression "oxidative stress" appears in the scientific literature in the 1970s. It implies that in aerobic organisms not only can molecular oxygen $\left(\mathrm{O}_{2}\right)$ be reduced to water in the biochemical process known as respiration, which requires 4 electrons, but $\mathrm{O}_{2}$ can also be reduced to other intermediate species, between $\mathrm{O}_{2}$ and water, resulting from 1-electron reductive steps (Figure 1). These intermediates are superoxide radical $\left(\mathrm{O}_{2}^{-}\right)$, hydrogen peroxide $\left(\mathrm{H}_{2} \mathrm{O}_{2}\right)$, and hydroxyl radical $(\mathrm{OH})$; they are all referred to as reactive oxygen species (ROS) and are extremely reactive because they avidly tend to reach the fully reduced state $\left(\mathrm{H}_{2} \mathrm{O}\right)$. Reactivity, in biological systems, is almost inevitably associated with toxicity, and ROS can damage various biological molecules: lipids (causing lipid peroxidation and membrane damage), DNA (causing DNA breaks), and proteins (causing, for instance, oxidation of various amino acids and inactivation of essential enzymes). 


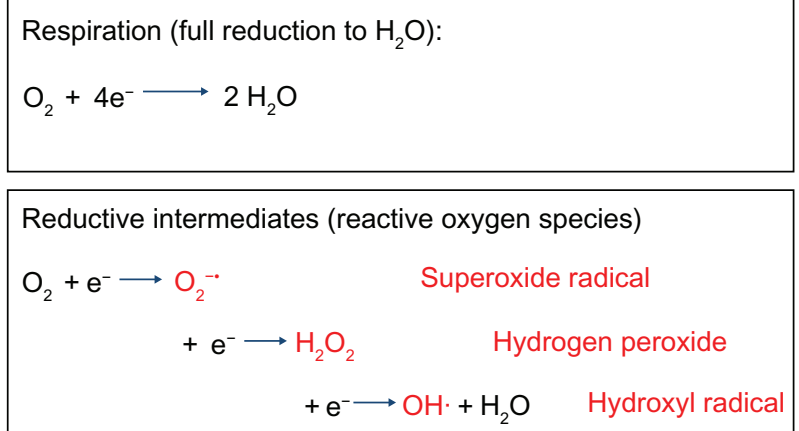

Figure I Reactive oxygen intermediates in the reductive metabolism of oxygen.

It is now thought that oxidative stress is implicated in the pathogenesis of several diseases and conditions, from aging to inflammation and carcinogenesis, if not as a primary cause of disease at least as an aggravating mechanism.

\section{Antioxidant defenses and glutathione}

The reality of oxidative stress is demonstrated by the existence, in all aerobic organisms, of several antioxidant enzymes devoted to ROS detoxification, such as peroxidase, catalase, superoxide dismutase, and peroxiredoxins. A number of small molecules also act as ROS scavengers. Unlike antioxidant enzymes, which catalyze the transformation of ROS into less toxic molecules, the concept of scavenger is that it must be an easily oxidizable target for ROS, and it must be present at concentrations high enough that the probability that a ROS reacts with the scavenger is higher than that of reacting with another target. When dealing with lipid oxidation (such as in rancidification of butter), the most important scavenger is probably vitamin $\mathrm{E}$. As proteins with a sulfydryl group are often target of oxidation (-SH groups can be easily oxidized), small-molecular-weight thiols are potent scavengers.

The small thiol present in highest concentration in the cytoplasm is glutathione (GSH), a tripeptide glycine-cysteineglutamic acid (Figure 2): the - $\mathrm{SH}$ group of its cysteine is extremely sensitive to oxidation, mainly by peroxides. Its importance is supported by the existence of a molecular machinery that makes it particularly effective. In fact, a scavenger, including any thiol antioxidant such as the common laboratory reagent beta-mercaptoethanol, would normally act as a suicidal decoy, being oxidized and thus becoming useless. However, when GSH is oxidized, it forms GSH disulfide (GSSG), and this can be re-reduced by a specific enzyme, glutathione reductase. Not only can GSH be enzymatically regenerated from GSSG, but also the

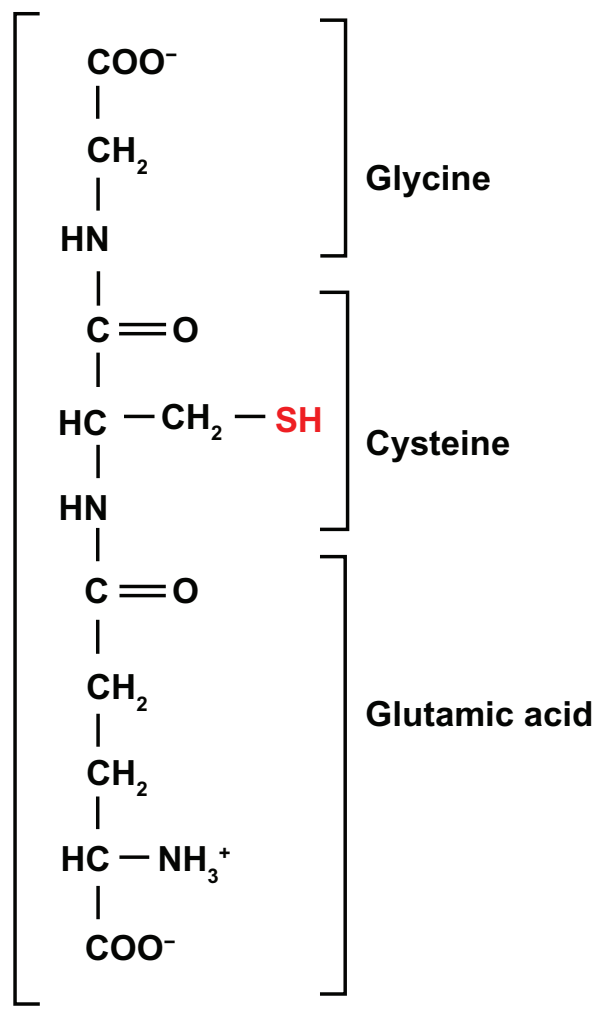

Figure 2 The tripeptide glutathione.

reaction of GSH with the ROS (a peroxide), which already takes place with high reactivity, is catalyzed by GSH peroxidases that facilitate the inactivation of a wide range of peroxides (Figure 3).

The key role of GSH as an antioxidant is demonstrated by many studies showing that experimental depletion of GSH levels - which can be achieved with various chemicals the most used of which is buthionine sulfoximine (BSO) an inhibitor of GSH synthesis - has a worsening effect in
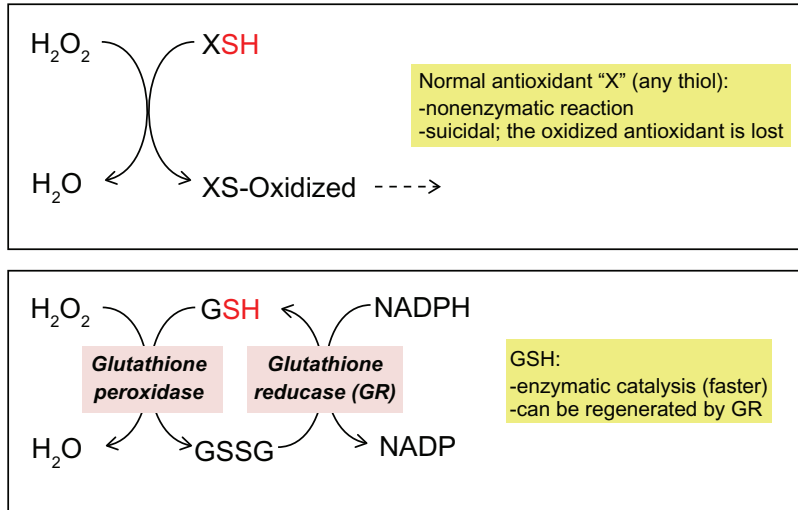

Figure 3 Glutathione: a very efficient antioxidant.

Abbreviation: GSSG, glutathione disulfide. 
many disease models. Conversely, repleting GSH levels with precursors of its synthesis such as $\mathrm{N}$-acetyl-cysteine (NAC) or 2-oxothiazolidine-4-carboxylic acid has protective effects. Cysteine precursors, rather than cysteine itself, are used because they are more cell-permeable, and can be given orally.

\section{Innate immunity and inflammation, two faces of the same biological coin}

The first line of immune defense against pathogens, before adaptive immunity (antibodies, $\mathrm{T}$ cell responses) develops, is called innate immunity. This is a complex set of responses triggered when specific cells (macrophages, phagocytes, dendritic cells) recognize even a yet unknown pathogen by some characteristics common to most pathogens (these "signatures" are called pathogen-associated molecular patterns) through a family of pathogen recognition receptors. This activates a response that involves production of ROS, a major bactericidal mechanism, and of soluble mediators (cytokines) whose role is to amplify the host response by recruiting and activating other immune system cells.

This aspect of the innate immune response is also known, from a different perspective, as the inflammatory response. Basically, the very same mechanisms and mediators of host defense are implicated in the pathogenesis of (noninfectious) inflammatory diseases, and inhibition of these mechanisms is the key to the mechanism of action of antiinflammatory drugs.

Many noninfectious diseases of the respiratory system, including asthma, chronic obstructive pulmonary disease (COPD), cystic fibrosis, idiopathic pulmonary fibrosis (IPF), and oxygen toxicity, have an inflammatory component. Inflammation is also implicated in the lung toxicity of ozone, asbestos, silica, cigarette smoke, and particulate matter. An exaggerated inflammatory response is also involved in the pathogenesis or complications of pulmonary infections such as tuberculosis, severe acute respiratory syndrome, influenza, and acute respiratory distress syndrome (ARDS).

\section{Glutathione metabolism in disease GSH synthesis and its precursors}

GSH is synthesized from its 3 amino acids with a biosynthetic pathway shown in Figure 4. A study in humans, using radioisotopes, ${ }^{3}$ has demonstrated that the availability of cysteine,and its precursor methionine, is the rate-limiting factor in GSH synthesis. In general, it is assumed that the

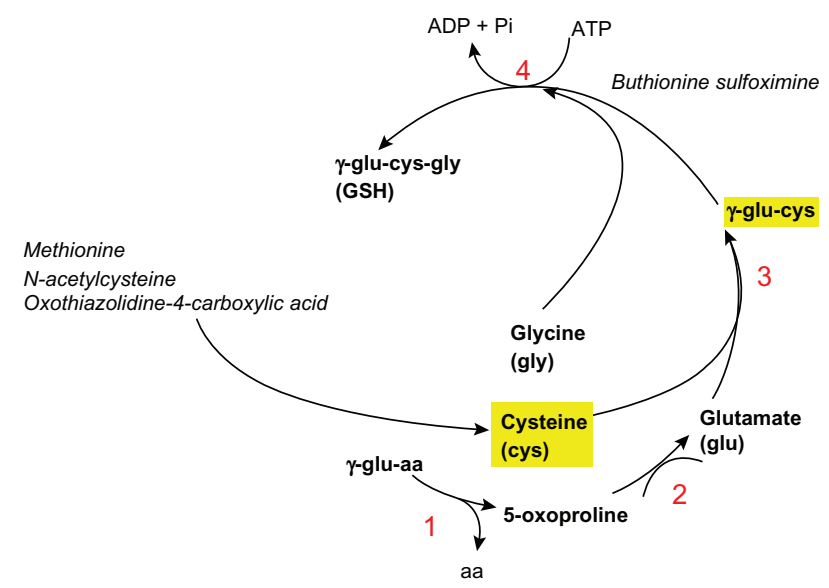

Figure 4 Glutathione (GSH) biosynthesis. I) gamma-glutamyl cyclotransferase; 2) 5-oxoprolinase; 3) gamma-glutamylcysteine synthetase; 4) Glutathione synthetase. Outlined in yellow are the limiting factors in GSH biosynthesis.

two main limiting factors are the levels of cysteine and of the enzyme gamma-glutamyl-cysteine synthetase (also known as glutamate-cysteine ligase). ${ }^{4}$

\section{Genetic GSH deficiency and immunity}

Glutathione synthetase (GS) deficiency (oxoprolinuria) is a rare autosomal recessive disorder affecting about 70 patients in the world. Patients with severe GS deficiency show, among other conditions, an increased susceptibility to bacterial infections. ${ }^{5,6}$

One case report showed that neutrophils from a child with GS deficiency undergo oxidative damage upon phagocytosis, indicating that GSH is important in defending the neutrophils from the ROS they produce as part of their microbicidal armamentarium. ${ }^{7}$ Of note, neutrophils from GS-deficient patients, despite normal phagocytosis and increased release of hydrogen peroxide, are less efficient in killing bacteria, indicating a helper role for GSH in the bactericidal activity. ${ }^{8}$

\section{Acquired GSH deficiency and immunity}

Many pathological conditions are associated with decreased GSH levels (Table 1). This could be due to several reasons. For instance, oxidative stress could cause GSH loss though oxidation. Another important aspect is nutrition, as it was shown that, even when dietary protein intake is sufficient for maintaining nitrogen balance, it may not be sufficient for maintaining cellular GSH, particularly in conditions of oxidative stress. ${ }^{9}$ GSH deficiency could also arise from metabolic problems. For instance, in AIDS patients, a decrease in gamma-cystathionase activity in the liver was reported. ${ }^{10}$ 
Table I Lung diseases associated with glutathione deficiency

Acute lung injury/acute respiratory distress syndrome

Chronic bronchitis

Chronic obstructive pulmonary disease

Cystic fibrosis

Idiopathic pulmonary fibrosis

Various bacterial and viral infections (including AIDS)

Toxicity of various foreign compound (smoke, pollutants, drugs ...)

The use of stable radioisotopes allowed the characterization of cysteine metabolism and GSH synthesis in septic patients. This study showed that sepsis decreases blood GSH synthesis by $60 \%{ }^{3}$ Of note, these patients had an intake of sulfur amino acids below that recommended by the World Health Organization. ${ }^{3}$ Studies in animal models have reported an increased requirement for cysteine in sepsis, probably due to an increased turnover of GSH, as GSH synthesis accounts for $40 \%$ of the increased cysteine utilization. ${ }^{11,12}$ These and other studies show that even when the dietary intake of cysteine is sufficient for protein synthesis (nitrogen balance), it may not be sufficient to maintain adequate GSH levels. ${ }^{9}$ One should also bear in mind that infectious and inflammatory conditions are associated with an increased production of acute-phase proteins by the liver, and it was estimated that they account significantly for the increased utilization of sulfur amino acids, thus competing with GSH. ${ }^{13,14}$

\section{GSH as a regulator of innate immunity Anti-inflammatory role of GSH in lung diseases}

The idea that GSH may play an anti-inflammatory role became popular in the 1990 s with a study by Schreck et al ${ }^{15}$ showing that antioxidants inhibit, whereas ROS activate, the transcription factor NF- $\kappa \mathrm{B}$ that commands the transcription of several inflammatory genes, ${ }^{16}$ a role that has been confirmed in the lung. ${ }^{17}$

In fact, a protective role of GSH against inflammatory pathologies of the lung has been demonstrated by the protective effect of different GSH-precursors in various animal models (Table 2).

Along the same line, depleting endogenous GSH with BSO had a worsening effect in some of the models above, including chemically induced pulmonary edema, ${ }^{21}$ cigarette smoke ${ }^{31}$ carrageenan-induced pleurisy, ${ }^{32}$ and endotoxininduced pulmonary inflammation. ${ }^{33}$

Table 2 Protective effect of glutathione repletion in lung diseases

\begin{tabular}{|c|c|c|c|c|}
\hline Disease & Species & $\begin{array}{l}\text { Compound } \\
\text { administered }\end{array}$ & Effect & Reference \\
\hline Asthma & mouse & $\begin{array}{l}\text { GSH-ethyl ester, } \\
\text { OTC }\end{array}$ & $\begin{array}{l}\text { Decreased allergen-induced } \\
\text { airway hyperresponsiveness } \\
\text { and inflammation }\end{array}$ & 18,19 \\
\hline $\begin{array}{l}\text { Carrageenan } \\
\text { pleurisy }\end{array}$ & rat & NAC & $\begin{array}{l}\text { Decreased inflammation and } \\
\text { oxidative stress; restored } \\
\text { mitochondrial respiration }\end{array}$ & 20 \\
\hline $\begin{array}{l}\text { Chemically } \\
\text { induced edema }\end{array}$ & rat & $\begin{array}{l}\text { NAC, cysteine } \\
\text { dimethyl ester }\end{array}$ & $\begin{array}{l}\text { Protection against lethal doses } \\
\text { of perfluoroisobutene }\end{array}$ & 21 \\
\hline $\begin{array}{l}\text { Idiopathic } \\
\text { pulmonary fibrosis }\end{array}$ & patients & NAC & $\begin{array}{l}\text { Preservation of vital capacity } \\
\text { and carbon monoxide diffusing } \\
\text { capacity }\end{array}$ & 22 \\
\hline $\begin{array}{l}\text { Bleomycin lung } \\
\text { damage }\end{array}$ & rat & NAC & $\begin{array}{l}\text { Decreased inflammation and } \\
\text { fibrosis (hydroxyproline } \\
\text { content) }\end{array}$ & 23 \\
\hline Asbestosis & rat & NAC & $\begin{array}{l}\text { Reduced chrysotile-induced } \\
\text { oxidative stress }\end{array}$ & 24 \\
\hline $\begin{array}{l}\text { Particulate matter } \\
\text { lung damage }\end{array}$ & rat & NAC & $\begin{array}{l}\text { Reduced histological } \\
\text { alterations and inflammation }\end{array}$ & 25 \\
\hline Hyperoxia & rat, guinea pig & OTC, NAC & $\begin{array}{l}\text { Reduced lung injury, alveolar } \\
\text { hemorrage, and edema }\end{array}$ & $26-28$ \\
\hline Cystic fibrosis & patients & NAC & Reduced inflammation & 29 \\
\hline $\begin{array}{l}\text { Smoke-induced } \\
\text { inflammation }\end{array}$ & rat & OTC & $\begin{array}{l}\text { Restoration of macrophage } \\
\text { phagocytic functions }\end{array}$ & 30 \\
\hline
\end{tabular}

Abbreviations: GSH, glutathione; NAC, N-acetylcysteine; OTC, oxothiazolidine-4-carboxylic acid. 
It can bee seen that there is an overlap between the list of pulmonary diseases associated with inflammation and those where GSH repletion is protective, indirectly supporting the hypothesis of an anti-inflammatory role of GSH.

An increased susceptibility to sepsis-induced ARDS and lethality ${ }^{34}$ was observed in mice lacking the transcription factor Nrf2, which has among its target genes the GSH biosynthetic enzyme gamma-glutamylcysteine synthase. ${ }^{35}$ IPF is an example of lung disease in which normalizing the GSH deficit has positive effects. Patients with IPF have a 4-fold lower GSH concentration in the epithelial lining fluid of the normal lower respiratory tract; ${ }^{36}$ moreover, the administration of the GSH precursor NAC not only restores GSH levels ${ }^{37}$ but, in association with other drugs used for the treatment of IPF, it also improves end points such as vital capacity and single-breath carbon monoxide diffusing capacity. $^{22}$

\section{GSH is essential for innate and adaptive immune functions}

The functions of GSH are not only inhibitory as described above for the inflammatory response. In fact, GSH is essential for some functions of the immune system, both innate and adaptive, including T-lymphocyte proliferation, ${ }^{38,39}$ phagocytic activity of polymorphonuclear neutrophils $(\mathrm{PMN}),{ }^{40}$ and dendritic cell functions, ${ }^{41}$ and is also important for the first step of adaptive immunity, consisting of the antigen presentation by antigen-presenting cells (APC). Indeed, cell-mediated immunity requires that protein antigens be first degraded in the endocytic vesicles of APCs (eg, macrophages, dendritic cells), so that the smaller peptides can be presented on the cell surface by the major histocompatibility complex to activate proliferation of antigen-specific $\mathrm{T}$ cells. One of the first steps in antigen degradation and processing is the reduction of disulfide bonds, ${ }^{42}$ which requires GSH. ${ }^{43}$ It should also be noted that although GSH inhibits the production of most inflammatory cytokines, it is required to maintain an adequate interferongamma (IFN-gamma) production by dendritic cells, ${ }^{44}$ which is essential for the host defense against intracellular pathogens such as mycobacteria. ${ }^{45}$

This essential role of GSH in immunity might explain why in many diseases, not only AIDS, decreased GSH levels are associated with an increased susceptibility to infection. These include COPD, ${ }^{46}$ cystic fibrosis, ${ }^{47,48}$ influenza infection, ${ }^{49}$ and alcoholism, ${ }^{50,51}$ as ethanol impairs Th1/Th2 balance via GSH depletion ${ }^{52}$ (Table 3).
Table 3 Glutathione (GSH) depletion is associated with increases susceptibility to infections

\begin{tabular}{ll}
\hline Condition & GSH \\
\hline Alcoholism & Infections \\
Chronic obstructive pulmonary disease & \\
Cystic fibrosis & \\
Influenza & \\
AIDS &
\end{tabular}

\section{GSH and immune defense against infection: four examples Example I: viral infections - oxidative stress and the pathogenesis of influenza}

The role of oxidative stress in the pulmonary damage by influenza virus is well characterized in the mouse model. Mice infected with influenza show pulmonary damage associated with a dramatic decrease in pulmonary GSH levels as well as an increase of oxidative stress markers such as oxidized glutathione (GSSG) and lipid peroxides. ${ }^{53}$ In these mice, oxidative stress could be due to the induction of xanthine oxidase, ${ }^{54}$ a well-known superoxide-generating enzyme. ${ }^{55}$ Furthermore, influenza infection is associated with an induction of inflammatory cytokines, ${ }^{56,57}$ which might represent a likely GSH-sensitive step in its pathogenesis. Among the antioxidants shown to be protective in animal models of influenza are the xanthine oxidase inhibitor allopurinol, ${ }^{54}$ quercetin, ${ }^{58}$ superoxide dismutase, ${ }^{59}$ thioredoxin, ${ }^{60}$ NAC (alone ${ }^{61}$ or with ribavirin ${ }^{62}$ or oseltamavir ${ }^{63}$ ), and GSH itself. ${ }^{64}$ A study reported that influenza virus M2 protein augments ROS production in human airway cells in vitro, resulting in toxic effects that are prevented by the addition of GSH ester. ${ }^{65}$ Although these studies indicate a protective role of GSH at the level of the pathogenesis of pulmonary damage, there is a report that BSO increases viral replication, ${ }^{66}$ implying a possible antiviral role of endogenous GSH. One clinical study has shown that NAC administration improves parameters of cell-mediated immunity in patients with influenza, ${ }^{66}$ suggesting a possible clinical relevance of these observations.

\section{Example 2: AIDS - importance of GSH in immunity}

Historically, the entire field of the role of GSH in immunity and its effect on NF- $\mathrm{KB}$ received the strongest boost by studies on AIDS, particularly by a study from the group of Wulf Droge who showed that AIDS patients have a low concentration 
of plasma cysteine ${ }^{67}$ The reasons for this are not clear, but AIDS patients have a deficit in the enzyme gamma cystathionase, which synthesizes cysteine from the methionine. ${ }^{10}$ Later research showed that AIDS causes a decrease in intracellular GSH in CD4 T cells, and that low GSH is associated with decreased survival. ${ }^{68}$

The lower GSH levels in AIDS patients could have various consequences. GSH depletion, at least in vitro, augments HIV replication, ${ }^{69}$ while its precursor NAC blocks the stimulatory effect of tumor necrosis factor on HIV replication. ${ }^{70}$ Furthermore, the neurotoxic effect of HIV proteins Tat and gp120 is associated with oxidative stress and antagonized by NAC..$^{71,72}$

\section{Example 3: bacterial infections - tuberculosis}

Mycobacterium tuberculosis is an intracellular pathogen that grows in the phagosomes, where it is protected from immune system effectors such as antibodies and $\mathrm{T}$ lymphocytes. Although the literature showing that GSH levels are lower in patients with tuberculosis dates back to the 1950s, it was not until the research of Venketaraman and colleagues that the effect of GSH on M. tuberculosis infection was studied in depth. Using a mouse macrophage cell line, the authors show that IFN-gamma and endotoxin increase both nitric oxide (NO) production and bactericidal activity; the paralleled decrease in GSH suggests that GSH reacts with NO to form S-nitrosoglutathione (GSNO). Under these experimental conditions, GSH depletion with BSO inhibited the microbicidal activity of macrophages while its precursor NAC increased intracellular killing of mycobacteria also from human macrophages, which are normally not very effective in killing mycobacteria. ${ }^{73,74}$ Other investigators have shown that the trans-sulfuration pathway, which converts methionine into cysteine and has a key role in maintaining cysteine, and hence GSH levels, is essential for mycobacterial killing. ${ }^{75}$ In that study, it was found that not only are trans-sulfuration pathway enzymes increased in human monocytes as a response to mycobacteria, but their inhibitor propargylglycine lowered GSH levels and inhibited clearance of mycobacteria and phagolysosome fusion, while NAC increased them. ${ }^{75}$ Similar results were obtained in whole human blood cultures. ${ }^{76}$ In vitro, both GSH and GSNO have direct bactericidal activity against these pathogens. ${ }^{77}$

This complex picture has been nicely reviewed by Connell and Venkataraman ${ }^{78}$ and is summarized in Figure 5. Depletion of GSH (by BSO or diethylmaleate) also inhibits macrophage leishmanicidal activity, as well as NO production, while the

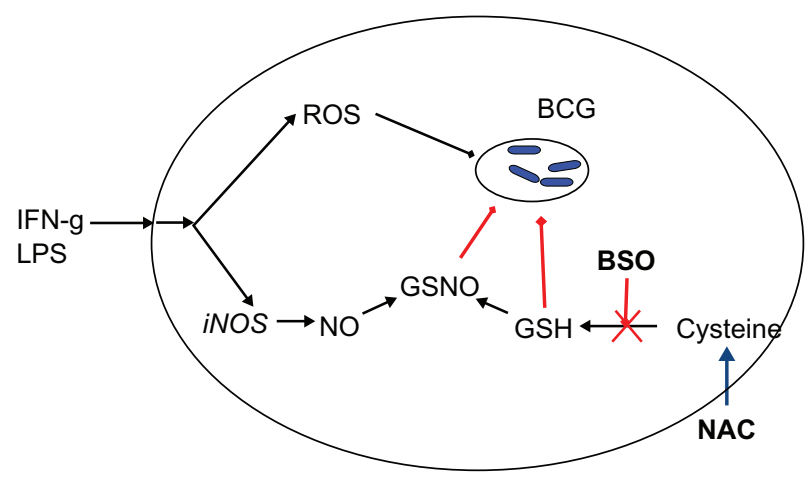

Figure 5 Glutathione in the defense against mycobacterial infections.

Abbreviations: IFN-g, interferon-gamma; LPS, lipopolysaccharide; ROS, reactive oxygen species; iNOS, inducible nitric oxide synthase; GSNO, S-nitrosoglutathione; GSH, glutathione; BCG, bacillus Calmette-Guérin; BSO, buthionine sulfoximine; NAC, N-acetyl-cysteine.

GSH precursor GSH-ethyl ester restores them, ${ }^{79}$ suggesting that the requirement for the GSH/NO pathway might be a common feature of resistance to intracellular pathogens.

\section{Example 4: sepsis and its complications - $\mathrm{GSH}$ as a regulatory molecule}

ARDS is one of the most serious complications in critically ill septic patients. Many studies have pointed out a role for oxidative stress in ARDS and shown a protective effect of GSH precursors. ${ }^{80,81}$

Most of the studies of ARDS in animal models, including those cited above, are based on the administration of lipopolysaccharide (LPS), a bacterial endotoxin. In mice, administration of LPS induces an acute lung injury similar to clinical ARDS, with production of inflammatory cytokines, leukocyte infiltration in the lung, and pulmonary edema. In this model, various thiol-based antioxidants are protective. ${ }^{80-82}$ However, LPS administration is in fact a model of endotoxic shock, involving no live bacteria, to induce a state similar to what was once called septic shock and is now defined as systemic inflammatory response syndrome..$^{83-85}$

However, in septic patients, survival is affected by 2 opposite contributions of innate immunity: innate immunity is detrimental as systemic inflammation, which results in ARDS and shock, but on the other hand it is an essential component of the immune defense against infection. It is difficult to foresee how GSH affects this balance.

One more realistic animal model is that induced by cecal ligation and puncture (CLP), where puncturing the cecum causes the release of fecal material in the peritoneum that results in a polymicrobial peritoneal sepsis. This model allows studying the relevance of both arms of innate immunity, the detrimental and the protective one. 


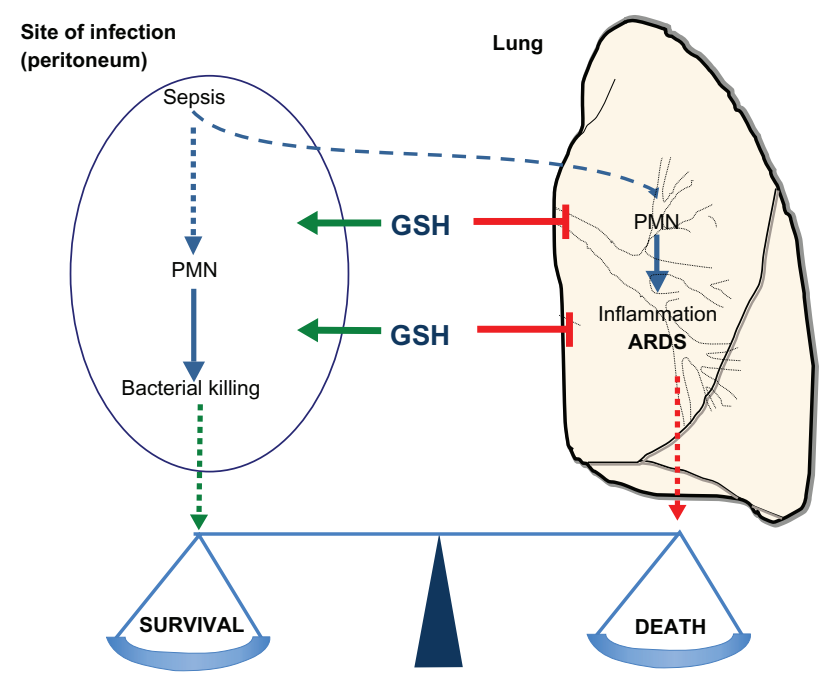

Figure 6 Glutathione regulates the balance between innate immunity or leukocyte infiltration at the site of infection to kill bacteria, and inflammation or leukocyte infiltration to the lung to cause organ failure.

Abbreviations: PMN, polymorphonuclear neutrophils; GSH, glutathione; ARDS, acute respiratory distress syndrome.

We have used this model to study the role of endogenous GSH in sepsis. ${ }^{86}$ In this model, CLP induced PMN infiltration in the peritoneal cavity, the site of infection, as well as in the lung, ultimately resulting in lung injury and death, with a concomitant decrease in endogenous GSH. ${ }^{86}$ Lowering GSH further with BSO worsened the clinical settings. Not only did BSO increase PMN infiltrate in the lung, but it also diminished PMN infiltration in the site of infection, thus increasing bacterial growth. As a result we had more inflammation and less immunity, and survival was dramatically decreased. Repleting GSH with NAC had the opposite effect of reducing PMN infiltration to the lung but increasing that to the site of infection, thus decreasing bacterial colonies.

The picture that emerges from these experiments is that endogenous GSH is not just an inhibitor of inflammation, but it is required to allow a proper response to infection, and "direct" the migration of inflammatory PMN away from the lung, where they cause ARDS, and towards the site of infection, where they kill bacteria (Figure 6).

The idea, therefore, is that GSH is not just an inhibitor of inflammation but also a regulator of innate immunity in a direction favorable to the host.

\section{Conclusions: GSH from a simple free-radical scavenger to a regulatory molecule}

In parallel to the studies of GSH in immunity, more complex molecular and biochemical studies have pointed out a regulatory role of GSH. This was a result of an evolution from the concept of oxidative stress outlined above to that of redox regulation. The concept of redox regulation implies that some oxidative changes (such as changes in the redox state of protein cysteines) are not necessarily damaging but can have regulatory properties. While this idea shows a more complex picture from the popular one where free radicals and oxidants are bad and antioxidants are good, it implies that GSH is an essential molecule not only in acting as an antioxidant but also in the absence of oxidative stress, as an endogenous signaling molecule. The molecular mechanisms of GSH-mediated redox regulation are being actively investigated and have in part been identified. ${ }^{87-89}$

Although the present review focused on the immuno pathogenesis of pulmonary diseases, the key concepts outlined here may help in interpreting the role of redox in other pathological conditions.

\section{Disclosure}

The author discloses no conflicts of interest.

\section{References}

1. Dormandy TL. Biological rancidification. Lancet. 1969;2(7622): 684-688.

2. Tappel A, Zalkin H. Inhibition of lipid peroxidation in microsomes by vitamin E. Nature. 1960;185:35.

3. Lyons J, Rauh-Pfeiffer A, Ming-Yu Y, et al. Cysteine metabolism and whole blood glutathione synthesis in septic pediatric patients. Crit Care Med. 2001;29(4):870-877.

4. Biolo G, Antonione R, De Cicco M. Glutathione metabolism in sepsis. Crit Care Med. 2007;35(9 Suppl):S591-S595.

5. Ristoff E, Larsson A. Inborn errors in the metabolism of glutathione. Orphanet J Rare Dis. 2007;2:16.

6. Ristoff E, Mayatepek E, Larsson A. Long-term clinical outcome in patients with glutathione synthetase deficiency. J Pediatr. 2001;139(1): 79-84.

7. Spielberg SP, Boxer LA, Oliver JM, Allen JM, Schulman JD. Oxidative damage to neutrophils in glutathione synthetase deficiency. Br J Haematol. 1979;42(2):215-223.

8. Boxer LA, Oliver JM, Spielberg SP, Allen JM, Schulman JD. Protection of granulocytes by vitamin $\mathrm{E}$ in glutathione synthetase deficiency. N Engl J Med. 1979;301(17):901-905.

9. Jackson AA, Gibson NR, Lu Y, Jahoor F. Synthesis of erythrocyte glutathione in healthy adults consuming the safe amount of dietary protein. Am J Clin Nutr. 2004;80(1):101-107.

10. Martin JA, Sastre J, de la Asuncion JG, Pallardo FV, Vina J. Hepatic gamma-cystathionase deficiency in patients with AIDS. JAMA. 2001; 285(11):1444-1445

11. Malmezat T, Breuille D, Capitan P, Mirand PP, Obled C. Glutathione turnover is increased during the acute phase of sepsis in rats. $J$ Nutr. 2000;130(5):1239-1246.

12. Malmezat T, Breuille D, Pouyet C, et al. Methionine transsulfuration is increased during sepsis in rats. Am J Physiol Endocrinol Metab. 2000; 279(6):E1391-E1397.

13. Hunter EA, Grimble RF. Cysteine and methionine supplementation modulate the effect of tumor necrosis factor alpha on protein synthesis, glutathione and zinc concentration of liver and lung in rats fed a low protein diet. J Nutr. 1994;124(12):2319-2328. 
14. Hunter EA, Grimble RF. Dietary sulphur amino acid adequacy influences glutathione synthesis and glutathione-dependent enzymes during the inflammatory response to endotoxin and tumour necrosis factor-alpha in rats. Clin Sci (Lond). 1997;92(3):297-305.

15. Schreck R, Rieber P, Baeuerle PA. Reactive oxygen intermediates as apparently widely used messengers in the activation of the NF-kappa B transcription factor and HIV-1. Embo J. 1991;10(8):2247-2258.

16. Baeuerle PA, Henkel T. Function and activation of NF-kappa B in the immune system. Annu Rev Immunol. 1994;12:141-179.

17. Blackwell TS, Blackwell TR, Holden EP, Christman BW, Christman JW. In vivo antioxidant treatment suppresses nuclear factor-kappa B activation and neutrophilic lung inflammation. J Immunol. 1996;157(4): $1630-1637$.

18. Kloek J, Van Ark I, De Clerck F, Bloksma N, Nijkamp FP, Folkerts G. Modulation of airway hyperresponsiveness by thiols in a murine in vivo model of allergic asthma. Inflamm Res. 2003;52(3):126-131.

19. Lee YC, Lee KS, Park SJ, et al. Blockade of airway hyperresponsiveness and inflammation in a murine model of asthma by a prodrug of cysteine, L-2-oxothiazolidine-4-carboxylic acid. FASEB J. 2004;18(15): 1917-1919.

20. Cuzzocrea S, Mazzon E, Dugo L, et al. Protective effects of $\mathrm{N}$-acetylcysteine on lung injury and red blood cell modification induced by carrageenan in the rat. FASEB J. 2001;15(7):1187-1200.

21. Lailey AF, Hill L, Lawston IW, Stanton D, Upshall DG. Protection by cysteine esters against chemically induced pulmonary oedema. Biochem Pharmacol. 1991;42 Suppl:S47-S54.

22. Demedts M, Behr J, Buhl R, et al. High-dose acetylcysteine in idiopathic pulmonary fibrosis. N Engl J Med. 2005;353(21):2229-2242.

23. Hagiwara SI, Ishii Y, Kitamura S. Aerosolized administration of $\mathrm{N}$-acetylcysteine attenuates lung fibrosis induced by bleomycin in mice. Am J Respir Crit Care Med. 2000;162(1):225-231.

24. Afaq F, Abidi P, Rahman Q. N-acetyl L-cysteine attenuates oxidantmediated toxicity induced by chrysotile fibers. Toxicol Lett. 2000; $117(1-2): 53-60$

25. Rhoden CR, Lawrence J, Godleski JJ, Gonzalez-Flecha B. $\mathrm{N}$-acetylcysteine prevents lung inflammation after short-term inhalation exposure to concentrated ambient particles. Toxicol Sci. 2004;79(2): 296-303.

26. Langley SC, Kelly FJ. N-acetylcysteine ameliorates hyperoxic lung injury in the preterm guinea pig. Biochem Pharmacol. 1993;45(4): 841-846.

27. Levy MA, Sikorski B, Bray TM. Selective elevation of glutathione levels in target tissues with L-2-oxothiazolidine-4-carboxylate (OTC) protects against hyperoxia-induced lung damage in protein-energy malnourished rats: implications for a new treatment strategy. J Nutr. 1998;128(4):671-676.

28. Lucas MC, Ludena MD, Barbero EA, Sanchez-Gascon F. Effects of $\mathrm{N}$-acetylcysteine on hyperoxic lung in the rat. Respir Med. 1995; 89(4):311.

29. Tirouvanziam R, Conrad CK, Bottiglieri T, Herzenberg LA, Moss RB. High-dose oral $\mathrm{N}$-acetylcysteine, a glutathione prodrug, modulates inflammation in cystic fibrosis. Proc Natl Acad Sci U SA. 2006;103(12): 4628-4633.

30. Hodge S, Matthews G, Mukaro V, et al. Cigarette smoke-induced changes to alveolar macrophage phenotype and function is improved by treatment with procysteine. Am J Respir Cell Mol Biol. Jul 1. [Epub ahead of print].

31. Park EM, Park YM, Gwak YS. Oxidative damage in tissues of rats exposed to cigarette smoke. Free Radic Biol Med. 1998;25(1):79-86.

32. Cuzzocrea S, Costantino G, Zingarelli B, Mazzon E, Micali A, Caputi AP. The protective role of endogenous glutathione in carrageenaninduced pleurisy in the rat. Eur J Pharmacol. 1999;372(2):187-197.

33. Haddad JJ. L-Buthionine-(S,R)-sulfoximine, an irreversible inhibitor of gamma-glutamylcysteine synthetase, augments LPS-mediated proinflammatory cytokine biosynthesis: evidence for the implication of an IkappaB-alpha/NF-kappaB insensitive pathway. Eur Cytokine Netw. 2001;12(4):614-624.
34. Thimmulappa RK, Lee H, Rangasamy T, et al. Nrf2 is a critical regulator of the innate immune response and survival during experimental sepsis. J Clin Invest. 2006;116(4):984-995.

35. Moinova HR, Mulcahy RT. Up-regulation of the human gammaglutamylcysteine synthetase regulatory subunit gene involves binding of Nrf-2 to an electrophile responsive element. Biochem Biophys Res Commun. 1999;261(3):661-668.

36. Cantin AM, Hubbard RC, Crystal RG. Glutathione deficiency in the epithelial lining fluid of the lower respiratory tract in idiopathic pulmonary fibrosis. Am Rev Respir Dis. 1989;139(2):370-372.

37. Meyer A, Buhl R, Magnussen H. The effect of oral N-acetylcysteine on lung glutathione levels in idiopathic pulmonary fibrosis. Eur Respir J. 1994;7(3):431-436.

38. Sido B, Braunstein J, Breitkreutz R, Herfarth C, Meuer SC. Thiolmediated redox regulation of intestinal lamina propria $\mathrm{T}$ lymphocytes. J Exp Med. 2000;192(6):907-912.

39. Hadzic T, Li L, Cheng N, Walsh SA, Spitz DR, Knudson CM. The role of low molecular weight thiols in T lymphocyte proliferation and IL-2 secretion. J Immunol. 2005;175(12):7965-7972.

40. Oliver JM, Albertini DF, Berlin RD. Effects of glutathione-oxidizing agents on microtubule assembly and microtubule-dependent surface properties of human neutrophils. J Cell Biol. 1976;71(3):921-932.

41. Kuppner MC, Scharner A, Milani V, et al. Ifosfamide impairs the allostimulatory capacity of human dendritic cells by intracellular glutathione depletion. Blood. 2003;102(10):3668-3674.

42. Arunachalam B, Phan UT, Geuze HJ, Cresswell P. Enzymatic reduction of disulfide bonds in lysosomes: characterization of a gamma-interferon-inducible lysosomal thiol reductase (GILT). Proc Natl Acad Sci U S A. 2000;97(2):745-750.

43. Short S, Merkel BJ, Caffrey R, McCoy KL. Defective antigen processing correlates with a low level of intracellular glutathione. Eur J Immunol. 1996;26(12):3015-3020.

44. Murata Y, Ohteki T, Koyasu S, Hamuro J. IFN-gamma and proinflammatory cytokine production by antigen-presenting cells is dictated by intracellular thiol redox status regulated by oxygen tension. Eur J Immunol. 2002;32(10):2866-2873.

45. Janeway CA, Travers P, Walport M, Shlomchik MJ. Immunobiology, 6th Edition. New York - London: Garland Science; 2005.

46. Parameswaran GI, Murphy TF. Infections in chronic lung diseases. Infect Dis Clin North Am. 2007;21(3):673-695, viii.

47. Sorensen RU, Waller RL, Klinger JD. Cystic fibrosis. Infection and immunity to Pseudomonas. Clin Rev Allergy. 1991;9(1-2):47-74.

48. Schroeder TH, Reiniger N, Meluleni G, Grout M, Coleman FT, Pier GB. Transgenic cystic fibrosis mice exhibit reduced early clearance of Pseudomonas aeruginosa from the respiratory tract. J Immunol. 2001; 166(12):7410-7418.

49. McNamee LA, Harmsen AG. Both influenza-induced neutrophil dysfunction and neutrophil-independent mechanisms contribute to increased susceptibility to a secondary Streptococcus pneumoniae infection. Infect Immun. 2006;74(12):6707-6721

50. Brown LA, Harris FL, Ping XD, Gauthier TW. Chronic ethanol ingestion and the risk of acute lung injury: a role for glutathione availability? Alcohol. 2004;33(3):191-197.

51. Nelson S, Kolls JK. Alcohol, host defence and society. Nat Rev Immunol. 2002;2(3):205-209.

52. Peterson JD, Herzenberg LA, Vasquez K, Waltenbaugh C. Glutathione levels in antigen-presenting cells modulate Th1 versus Th2 response patterns. Proc Natl Acad Sci U S A. 1998;95(6):3071-3076.

53. Suliman HB, Ryan LK, Bishop L, Folz RJ. Prevention of influenzainduced lung injury in mice overexpressing extracellular superoxide dismutase. Am J Physiol Lung Cell Mol Physiol. 2001;280(1): L69-L78.

54. Akaike T, Ando M, Oda T, et al. Dependence on O2- generation by xanthine oxidase of pathogenesis of influenza virus infection in mice. J Clin Invest. 1990;85(3):739-745.

55. McCord JM, Fridovich I. The reduction of cytochrome c by milk xanthine oxidase. J Biol Chem. 1968;243(21):5753-5760. 
56. Wang JP, Bowen GN, Padden C, et al. Toll-like receptor-mediated activation of neutrophils by influenza A virus. Blood. 2008;112(5): 2028-2034.

57. de Jong MD, Simmons CP, Thanh TT, et al. Fatal outcome of human influenza A (H5N1) is associated with high viral load and hypercytokinemia. Nat Med. 2006;12(10):1203-1207.

58. Kumar P, Sharma S, Khanna M, Raj HG. Effect of Quercetin on lipid peroxidation and changes in lung morphology in experimental influenza virus infection. Int J Exp Pathol. 2003;84(3):127-133.

59. Oda T, Akaike T, Hamamoto T, Suzuki F, Hirano T, Maeda H. Oxygen radicals in influenza-induced pathogenesis and treatment with pyran polymer-conjugated SOD. Science. 1989;244(4907):974-976.

60. Nakamura H, Tamura S, Watanabe I, Iwasaki T, Yodoi J. Enhanced resistancy of thioredoxin-transgenic mice against influenza virusinduced pneumonia. Immunol Lett. 2002;82(1-2):165-170.

61. Ungheri D, Pisani C, Sanson G, et al. Protective effect of N-acetylcysteine in a model of influenza infection in mice. Int $J$ Immunopathol Pharmacol. 2000;13(3):123-128.

62. Ghezzi P, Ungheri D. Synergistic combination of N-acetylcysteine and ribavirin to protect from lethal influenza viral infection in a mouse model. Int J Immunopathol Pharmacol. 2004;17(1):99-102.

63. Garozzo A, Tempera G, Ungheri D, Timpanaro R, Castro A. $\mathrm{N}$-acetylcysteine synergizes with oseltamivir in protecting mice from lethal influenza infection. Int J Immunopathol Pharmacol. 2007;20(2): 349-354.

64. Cai J, Chen Y, Seth S, Furukawa S, Compans RW, Jones DP. Inhibition of influenza infection by glutathione. Free Radic Biol Med. 2003;34(7): 928-936.

65. Lazrak A, Iles KE, Liu G, Noah DL, Noah JW, Matalon S. Influenza virus M2 protein inhibits epithelial sodium channels by increasing reactive oxygen species. FASEB J. 2009;23(11):3829-3842.

66. Nencioni L, Iuvara A, Aquilano K, et al. Influenza A virus replication is dependent on an antioxidant pathway that involves $\mathrm{GSH}$ and $\mathrm{Bcl}-2$. FASEB J. 2003;17(6):758-760.

67. Eck HP, Gmunder H, Hartmann M, Petzoldt D, Daniel V, Droge W. Low concentrations of acid-soluble thiol (cysteine) in the blood plasma of HIV-1-infected patients. Biol Chem Hoppe Seyler. 1989;370(2): $101-108$.

68. Herzenberg LA, De Rosa SC, Dubs JG, et al. Glutathione deficiency is associated with impaired survival in HIV disease. Proc Natl Acad Sci US A. 1997;94(5):1967-1972.

69. Garaci E, Palamara AT, Ciriolo MR, et al. Intracellular GSH content and HIV replication in human macrophages. J Leukoc Biol. 1997;62(1): 54-59.

70. Roederer M, Staal FJ, Raju PA, Ela SW, Herzenberg LA. Cytokinestimulated human immunodeficiency virus replication is inhibited by N-acetyl-L-cysteine. Proc Natl Acad Sci U S A. 1990;87(12): 4884-4888.

71. $\mathrm{Pu}$ H, Tian J, Andras IE, et al. HIV-1 Tat protein-induced alterations of ZO-1 expression are mediated by redox-regulated ERK 1/2 activation. $J$ Cereb Blood Flow Metab. 2005;25(10):1325-1335.

72. Visalli V, Muscoli C, Sacco I, et al. N-acetylcysteine prevents HIV gp 120-related damage of human cultured astrocytes: correlation with glutamine synthase dysfunction. BMC Neurosci. 2007;8:106.
73. Venketaraman V, Dayaram YK, Amin AG, et al. Role of glutathione in macrophage control of mycobacteria. Infect Immun. 2003;71(4): 1864-1871.

74. Venketaraman V, Dayaram YK, Talaue MT, Connell ND. Glutathione and nitrosoglutathione in macrophage defense against Mycobacterium tuberculosis. Infect Immun. 2005;73(3):1886-1889.

75. Garg S, Vitvitsky V, Gendelman HE, Banerjee R. Monocyte differentiation, activation, and mycobacterial killing are linked to transsulfuration-dependent redox metabolism. J Biol Chem. 2006; 281(50): 38712-38720.

76. Venketaraman V, Millman A, Salman M, et al. Glutathione levels and immune responses in tuberculosis patients. Microb Pathog. 2008;44(3): 255-261.

77. Green RM, Seth A, Connell ND. A peptide permease mutant of Mycobacterium bovis BCG resistant to the toxic peptides glutathione and S-nitrosoglutathione. Infect Immun. 2000;68(2):429-436.

78. Connell ND, Venketaraman V. Control of mycobacterium tuberculosis infection by glutathione. Recent Pat Antiinfect Drug Discov. 2009;4(3): 214-226.

79. Buchmuller-Rouiller Y, Corrandin SB, Smith J, et al. Role of glutathione in macrophage activation: effect of cellular glutathione depletion on nitrite production and leishmanicidal activity. Cell Immunol. 1995; 164(1):73-80.

80. Davreux CJ, Soric I, Nathens AB, et al. N-acetyl cysteine attenuates acute lung injury in the rat. Shock. 1997;8(6):432-438.

81. Gatti S, Faggioni R, Echtenacher B, Ghezzi P. Role of tumour necrosis factor and reactive oxygen intermediates in lipopolysaccharide-induced pulmonary oedema and lethality. Clin Exp Immunol. 1993;91(3): 456-461.

82. Bernard GR, Lucht WD, Niedermeyer ME, Snapper JR, Ogletree ML, Brigham KL. Effect of N-acetylcysteine on the pulmonary response to endotoxin in the awake sheep and upon in vitro granulocyte function. J Clin Invest. 1984;73(6):1772-1784.

83. ACCP. American College of Chest Physicians/Society of Critical Care Medicine Consensus Conference: definitions for sepsis and organ failure and guidelines for the use of innovative therapies in sepsis. Crit Care Med. 1992;20(6):864-874.

84. Bone RC. Sepsis and its complications: the clinical problem. Crit Care Med. 1994;22(7):S8-S11.

85. Redl H, Schlag G, Bahrami S, Yao YM. Animal models as the basis of pharmacologic intervention in trauma and sepsis patients. World J Surg. 1996;20(4):487-492.

86. Villa P, Saccani A, Sica A, Ghezzi P. Glutathione protects mice from lethal sepsis by limiting inflammation and potentiating host defense. J Infect Dis. 2002;185(8):1115-1120.

87. Ghezzi P, Di Simplicio P. Glutathionylation pathways in drug response. Curr Opin Pharmacol. 2007;7(4):398-403.

88. Ghezzi P. Oxidoreduction of protein thiols in redox regulation. Biochem Soc Trans. 2005;33(Pt 6):1378-1381.

89. Ghezzi P. Regulation of protein function by glutathionylation. Free Radic Res. 2005;39(6):573-580.
International Journal of General Medicine

\section{Publish your work in this journal}

The International Journal of General Medicine is an international, peer-reviewed open-access journal that focuses on general and internal medicine, pathogenesis, epidemiology, diagnosis, monitoring and treatment protocols. The journal is characterized by the rapid reporting of reviews, original research and clinical studies across all disease areas.

\section{Dovepress}

A key focus is the elucidation of disease processes and management protocols resulting in improved outcomes for the patient. The manuscript management system is completely online and includes a very quick and fair peer-review system. Visit http://www.dovepress.com/ testimonials.php to read real quotes from published authors. 